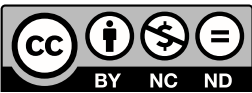

Estudos Teológicos foi licenciado com uma Licença Creative Commons Atribuição - NãoComercial - SemDerivados 3.0 Não Adaptada

http://dx.doi.org/10.22351/etv59i2.3491

\title{
O ABORTO SELETIVO COMO CAMINHO PARA O INFANTICÍDIO ${ }^{1}$
}

\author{
Selective abortion as path to infanticide
}

\section{Euler Renato Westphal ${ }^{2}$ Arlindo Ferretti Junior ${ }^{3}$}

\begin{abstract}
Resumo: Em muitos países é possível optar pelo aborto em caso de diagnóstico de anomalias fetais. Alguns intelectuais, como Peter Singer, Francesca Minerva e Alberto Giubilini, entendem e defendem, a partir de uma visão ética utilitarista, que sob a mesma justificativa o infanticídio torna-se moralmente correto. Esses filósofos são claros em suas conclusões, e é nesse contexto que este artigo propõe discutir algumas das consequências dessa visão de mundo. Utilizando o método bibliográfico, procuramos dar forma a essa discussão, apresentando o caso da síndrome de Down. Aludindo à impossibilidade, sob a justificativa utilitarista, de se defender o aborto e rejeitar o infanticídio, como proposto por Henrik Friberg-Fernros, apresentamos a perspectiva humanista, em diálogo com Jürgen Habermas e Hannah Arendt, como contraposição ao relativismo ético. Os autores deste artigo concluem que, se moralmente aceito, como forma de eliminação do sofrimento e garantia da qualidade de vida, o aborto seletivo abre caminho para a viabilidade moral do infanticídio. Palavras-chave: Aborto seletivo. Infanticídio. Ética utilitarista.
\end{abstract}

Abstract: In many countries it is possible to choose abortion in case of diagnosis of fetal anomalies. Some intellectuals, such as Peter Singer, Francesca Minerva and Alberto Giubilini, understand and defend, from a utilitarian point of view, that under the same justification, infanticide becomes morally correct. These philosophers are clear in their conclusions, and it is in this context that this article proposes to discuss some of the consequences of this worldview. Using the bibliographic method, we try to give form to this discussion, presenting the case of Down syndrome. Referring to the impossibility, under the utilitarian justification, of defending abortion and rejecting infanticide, as proposed by Henrik Friberg-Fernros, we present the humanist perspective, in dialogue with Jürgen Habermas and Hannah Arendt, as a counterpoint to ethical relativism. The authors of this article conclude that, if morally accepted as a way of eliminating suffering and guaranteeing the quality of life, selective abortion opens the way to the moral viability of infanticide.

Keywords: Selective abortion. Infanticide. Utilitarianism.

1 O artigo foi recebido em 18 de outubro de 2018 e aprovado em 22 de julho de 2019 com base nas avaliações dos pareceristas ad hoc.

2 Doutor. Universidade da Região de Joinville - UNIVILLE, Joinville, SC. Faculdade Luterana de Teologia - FLT, São Bento do Sul, SC. "O presente trabalho foi realizado com apoio da Coordenação de Aperfeiçoamento de Pessoal de Nível Superior - Brasil (CAPES) - Código de Financiamento 001." E-mail: eulerwestphal@gmail.com

3 Graduado. Universidade da Região de Joinville-UNIVILE, Joinville, SC. E-mail: jnferretti@gmail.com 


\section{Introdução}

As discussões a respeito da legalidade dos procedimentos abortivos são pauta frequente no âmbito internacional. As recentes aprovações do procedimento, como no caso irlandês ${ }^{4}$, e reprovações, a exemplo da Argentina ${ }^{5}$, bem como as discussões levadas a cabo pelo Supremo Tribunal Federal no que tange a Ação de Descumprimento de Preceito Fundamental (ADPF) $442^{6}$, trazem à tona uma retomada dos debates sobre o tema. Embora a legislação mundial dê sinais de que se encaminha para a gradual liberalização, algumas questões éticas, imbricadas nas justificativas para a realização do procedimento, não podem ser ignoradas. Uma dessas questões emerge das seletividades diversas que regem a decisão por continuar, ou não, com a gestação, após os primeiros exames pré-natais.

A síndrome de Down é a anormalidade cromossômica mais comum na espécie humana, sendo também a maior propiciadora de deficiência mental. ${ }^{7}$ De maneira geral, a alteração não pode ser evitada por meio de tratamentos. Embora seja reconhecida a prevalência da condição em crianças geradas por mães com idade maior que $35 \operatorname{anos}^{8}$, até agora não foi possível encontrar respostas concretas para explicar essa mutação. A incapacidade de se prevenir a ocorrência da alteração genética levanta uma série de problemas éticos, decorrentes da única alternativa para evitar o aumento demográfico dos indivíduos com esse tipo de aneuplodia ${ }^{9}$, qual seja, a utilização de diagnósticos pré-natais, objetivando a identificação e posterior interrupção da gestação de fetos afetados pela alteração.

A mutação cromossômica geradora da síndrome de Down foi descoberta em 1959, e o diagnóstico pré-natal é, geralmente, realizado por meio de um dos dois procedimentos invasivos: a punção de vilosidades coriônicas (PVC) e a amniocentese, que possuem entre $97,5 \%$ e $99,8 \%$ de precisão. Uma combinação de exames de ultrassonografia e análises bioquímicas do sangue da mãe tem mostrado taxas altas de detecção, entre $75 \%$ e $96 \%$, possibilitando um menor uso dos procedimentos de PVC e amniocentese, evitando-se os riscos desses para a saúde da mulher e do feto. ${ }^{10}$

4 REILLY, Gavan. Vitória pró-aborto na Irlanda surpreende até mesmo ativistas. Deutsche Welle, 2018. Disponível em: < https://www.dw.com/pt-br/vit\%C3\%B3ria-pr\%C3\%B3-aborto-na-irlanda-surpreendeat\%C3\%A9-mesmo-ativistas/a-43951449>. Acesso em: 29 out. 2018.

5 SCHREIBER, Mariana. Senado argentino barra legalização do aborto; países latino-americanos são os que mais restringem a prática no mundo. BBC Brasil, 2018. Disponível em: <https://www.bbc.com/ portuguese/geral-45126092>. Acesso em: 29 out. 2018.

6 CREMESP-CENTRO DE BIOÉTICA. STF promove audiência pública sobre o Início da Vida. CREMESP - Centro de Bioética, 2018. Disponível em: <http://www.bioetica.org.br/?siteAcao=Destaques\&id=91>. Acesso em: 29 out. 2018.

7 NORWITZ, Errol R.; LEVY, Brynn. Noninvasive Prenatal Testing: The Future Is Now. Reviews in Obstetrics and Gynecology, v. 6, n. 2, p. 48-62, 2013. p. 49

8 NORWITZ; LEVY, 2013.

9 Alteração irregular no número de cromossomos.

10 NORWITZ; LEVY, 2013. 
Uma pesquisa de 2008, conduzida por P. A. Boyd et al., revelou que, em casos de diagnóstico pré-natal da condição, a taxa de interrupções passa dos $90 \%$ na Suíça e na Bélgica, chegando a 96\% na França, Alemanha, Itália e Espanha. ${ }^{11}$ Isso é dizer que menos do que uma gravidez em dez, após a detecção da síndrome, é levada até o nascimento. Procurando esclarecer os altos índices de aborto após o diagnóstico, Robert Cole e David Gareth Jones ${ }^{12}$ indicam que a maior parte das mulheres que não abortariam em nenhuma circunstância não se submete a esse tipo de exame, o que resulta na reduzida quantidade de gestações mantidas após o diagnóstico.

Essa informação, todavia, não permite que se ignore que, nos casos acima citados, a seletividade sobre a manutenção ou não da gravidez se dá apenas após o recebimento da nova informação, e isso implica, como indica Henrik Friberg-Fernros,

[...] que se pode, então, assumir que não é a informação sobre a gravidez que leva à decisão sobre o aborto, mas a informação tardia a respeito da Síndrome de Down. Além disso, o fato de o feto ter Síndrome de Down não gera, ele mesmo, um fardo extra durante a gravidez: o fardo extra é esperado para depois do nascimento ${ }^{13}$.

Assim, o aborto em questão é realizado em razão da condição genética do feto. Se há fundo eugênico nessa postura, não é o objetivo deste artigo investigar. Ao invés disso, propomos que se leve a legalidade do aborto nessas condições ao seu desdobramento lógico, o after-birth abortion ${ }^{14}$ dos recém-nascidos nessas condições. Nos próximos parágrafos, procuramos elucidar a relação e apontar alguns dos fundamentos éticos dessa conclusão.

\section{O sofrimento humano e o aborto seletivo}

O cientista Richard Dawkins afirmou em seu Twitter, no dia 20 de agosto de 2014, como resposta a uma usuária que disse não saber o que faria se estivesse grávida de uma criança com síndrome de Down: "Aborte e tente de novo. Seria imoral trazer

11 BOYD, P. A. et al. Survey of prenatal screening policies in Europe for structural malformations and chromosome anomalies, and their impact on detection and termination rates for neural tube defects and Down's syndrome. Bjog, v. 115, n. 6, p. 689, 2008.

12 COLE, Robert; JONES, David. Testing times: do new prenatal tests signal the end of Down syndrome? The New Zealand medical journal, v. 126, p. 96-102, 2013.

13 " [...] that one can therefore assume that it is not the information about the pregnancy that leads to the decision to abort, but rather, the later information about Down syndrome. Moreover, the fact that a fetus has Down syndrome does not in itself generate an extra burden during pregnancy: rather, the extra burden is expected to occur after birth." FRIBERG-FERNROS, Henrik. Clashes of consensus: on the problem of both justifying abortion of fetuses with Down syndrome and rejecting infanticide. Theoretical Medicine and Bioethics, v. 38, n. 3, p. 195-212, 2017. p. 210. As traduções são nossas. Apenas termos específicos não serão traduzidos no corpo do texto.

14 “Aborto pós-nascimento." GIUBILINI, Alberto; MINERVA, Francesca. After-birth abortion: why should the baby live? Journal of Medical Ethics, p. medethics-2011-100411, 2012. 
isso ao mundo se você pode escolher"'15. A posição de Dawkins, embora não tenha soado bem aos ouvidos de muitos de seus seguidores, reflete uma mentalidade que, como as estatísticas supracitadas demonstram, é bastante difundida. A postura revela o interesse no desvio de uma pressuposta fonte de desprazer. O bebê com Down seria uma espécie de obstáculo para a felicidade plena. ${ }^{16}$

Nesse mesmo sentido, Ruth Marcus, jornalista americana que escreve para o The Washington Post, publicou recentemente, em sua coluna no jornal, um artigo intitulado "Eu teria abortado um feto com síndrome de Down. As mulheres precisam desse direito" "17. A autora critica a crescente pressão do poder legislativo de algumas unidades administrativas do país que colocaram em debate a proibição do procedimento de interrupção da gravidez em casos de diagnóstico de síndrome de Down. Dar à luz uma criança nessas condições, indica a autora, é aceitar uma série de limitações e prejuízos para o bem-estar de toda a família, daí a inconstitucionalidade de uma lei proibitiva.

Em 2016, o Conselho Superior de Audiovisual da França proibiu a circulação do vídeo intitulado "Querida Futura Mãe"18, elaborado por organizações de apoio às pessoas com síndrome de Down. ${ }^{19}$ Após apelo público, o Conselho de Estado francês divulgou nota mantendo a proibição e alegando a possibilidade de que o vídeo pudesse "gerar distúrbios de consciência nas mulheres que, de acordo com a lei, haviam feito decisões particulares de vida" ${ }^{20}$. Segundo seus idealizadores, o intuito do vídeo era demonstrar que, na realidade, tanto as crianças com essa condição como seus familiares poderiam também viver felizes. De fato, como mostram estudos recentes, pessoas com síndrome de Down revelam altos índices de satisfação e felicidade pessoal. ${ }^{21}$

15 "Abort it and try again. It would be immoral to bring it into the world if you have the choice." BINGHAM, John. Richard Dawkins: 'immoral' to allow Down's syndrome babies to be born. The Telegraph, 2014. Disponível em: <https:/www.telegraph.co.uk/news/health/news/11047072/Richard-Dawkins-immoralto-allow-Downs-syndrome-babies-to-be-born.html>. Acesso em: 29 out. 2018.

16 Posição que se torna evidente quando Dawkins afirma, em um artigo posterior em seu próprio site, que "[...] if your morality is based, as mine is, on a desire to increase the sum of happiness and reduce suffering, the decision to deliberately give birth to a Down baby, when you have the choice to abort it [...] might actually be immoral [...]" (nosso destaque). DAWKINS, Richard. Abortion \& Down Syndrome: An Apology for Letting Slip the Dogs of Twitterwar. Richard Dawkins, 2014. Disponível em: <https:/www.richarddawkins. net/2014/08/abortion-down-syndrome-an-apology-for-letting-slip-the-dogs-of-twitterwar/>. Acesso em: 29 out. 2018.

17 “MARCUS, Ruth. I would've aborted a fetus with Down syndrome. Women need that right. Washington Post, 2018. Disponível em: <https://www.washingtonpost.com/opinions/i-wouldve-aborted-a-fetus-withdown-syndrome-women-need-that-right/2018/03/09/3aaac364-23d6-11e8-94da-ebf9d112159c_story. html?utm_term=.83dc1a90867b>. Acesso em: 29 out. 2018.

18 "Dear Future Mom", no original.

19 BURKE, Dave. Outcry after French court rules that pro-life commercial showing happy children with Down syndrome was 'inappropriate' and 'likely to disturb women' who had abortions. Dailymail, 2016. Disponível em: <https://www.dailymail.co.uk/news/article-3970656/Outcry-French-court-rules-pro-lifecommercial-showing-happy-children-syndrome-inappropriate-likely-disturb-women-abortions.html >. Acesso em: 29 out. 2018.

${ }^{20}$ BURKE, 2016.

${ }^{21}$ Cf. SKOTKO, Brian G.; LEVINE, Susan P.; GOLDSTEIN, Richard. Self-perceptions from People with Down Syndrome. American journal of medical genetics, Part A, v. 0, n. 10, p. 2.360-2.369, 2011. 
Percebe-se, portanto, que nos exemplos citados está presente uma compreensão de que, a fim de se evitar um determinado fardo para os indivíduos envolvidos na potencialidade de se criar uma criança com síndrome de Down, seria legítimo interromper a gestação, ou evitar a propagação de materiais que possam causar prejuízo emocional aos que escolham terminar a gravidez. Essa problemática, então, parece desenvolver-se por uma rota ética particular, que é exposta também pelos filósofos Alberto Giubilini e Francesa Minerva. Em 2012, os autores publicaram um artigo no qual defendem uma proposta para os casos em que a decisão sobre a realização do aborto só seja tomada após o parto, incluindo os casos de falha no diagnóstico prévio:

[...] trazer essa criança à vida pode ser um fardo impossível de ser carregado pela família e pela sociedade como um todo, quando é o Estado quem fornece os cuidados. ${ }^{22}$ Nesse contexto, o fato de que o feto tem o potencial para ter uma vida minimamente aceitável não é razão para proibir o aborto. Assim, nós argumentamos que, quando o diagnóstico que justificaria o aborto ocorre depois do nascimento, o que nós chamamos de after-birth abortion deveria ser permitido ${ }^{23}$.

\section{A ética do infanticídio}

O filósofo australiano Peter Singer propõe o infanticídio - não apenas para casos de anomalias genéticas - como uma atitude moralmente correta. Para o teórico, qualquer discussão sobre o aborto deve levar em conta uma questão fundamental: é errado matar seres humanos $?^{24}$. Do seu ponto de vista, é a autoconsciência que define a pessoalidade dos indivíduos. Assim, só pode ser considerada uma pessoa o membro da espécie humana que seja "[...] autônomo, capaz de fazer escolhas [...]"25, o que evidentemente feto e neonato não são. Por isso, considera o filósofo, embriões, fetos e crianças recém-nascidas, embora pertençam à espécie humana, não têm dignidade nenhuma e podem ser mortos sem que sejam violados quaisquer direitos próprios.

A dignidade humana como concessão transcendental é reprovada por Singer. $\mathrm{O}$ autor tece críticas à religião cristã que é, para ele, origem da ideia de que assassinar alguém é algo terrível, já que nela, “[...] tendo sido criados por Deus, é a ele que pertencemos, e matar um ser humano equivale a usurpar o direito divino de decidir quando devemos viver e quando devemos morrer"26. A dignidade não pode, para o autor, ter origem fora, mas apenas dentro dos indivíduos, dado que "[...] o direito à

22 A preocupação com os custos públicos para o cuidado dos mais frágeis pode ser vista também em GOLLOP, Thomaz Rafael. Aborto por Anomalia Fetal. Revista Bioética, v. 2, n. 1, 2009. p. 4.

23 " [...] to bring up such children might be an unbearable burden on the Family and on society as a whole, when the state economically provides for their care. On these grounds, the fact that a fetus has the potential to become a person who will have an (at least) acceptable life is no reason for prohibiting abortion." GIUBILINI; MINERVA, 2012, p. 2.

24 SINGER, Peter. Practical Ethics: Second Edition. New York: Cambridge University Press, 1999.

25 “[...] autonomous being, capable of making choices." SINGER, 1999, p. 171.

26 " [...] since we are created by God we are his property, and to kill a human being is so to usurp God's right to decide when we shall live and when we shall die." SINGER, 1999, p. 89. 
vida deve ter por base a capacidade de querer continuar vivo, ou a capacidade de ver-se como sujeito mental contínuo [...]" e, por isso, “[...] um recém-nascido não pode ter direito à vida" 27 .

Assim sendo, na mesma lógica aceita para a decisão por abortar fetos diagnosticados com alguma síndrome genética, Singer afirma que “[...] o infanticídio pode ser comparado ao aborto quando as pessoas mais próximas da criança não quiserem ela viva"28. Ou seja: só pode ser considerado moralmente incorreto eliminar um feto ou um recém-nascido se tal atitude provocar sofrimento nos envolvidos - se, pelo contrário, o descarte gerar felicidade, ele não só é aceitável do ponto de vista da ética utilitarista, como incentivado, principalmente se houver intenção, por exemplo, de se realizar pesquisas com o tecido fetal, já que essa poderia beneficiar um grande número de pessoas. Singer orienta-se no princípio do utilitarismo clássico, que considera serem éticas ações que proporcionam o aumento da felicidade coletiva. Assim, a sensibilidade de sentir felicidade e sofrimento é o critério ético para a preocupação com interesses alheios. Segundo o autor, o critério da autonomia, princípio fundamental da bioética principialista, estaria subordinado ao critério da maximização da alegria e da minimização de sofrimento. Singer discute, a partir dessa perspectiva, a questão do sofrimento na relação abusiva do ser humano com os animais, que não iremos tratar neste artigo em virtude das limitações de espaço. ${ }^{29}$

Para entender melhor a visão utilitarista, nos ocuparemos com a concepção de dignidade humana criticada por Singer. Segundo ele, filósofos como Jürgen Habermas estão inseridos na tradição da ética universal humanista cristã. ${ }^{30}$ De fato, Habermas, como intérprete de Kant, ressalta a dimensão cristológica da dignidade humana como valor universal. $\mathrm{O}$ autor indica que os critérios morais adotados no Ocidente são derivados de uma secularização do sermão da montanha feita por Kant, e expressa no seu universalismo igualitário. ${ }^{31}$ Assim, a dignidade humana é garantida pela relação com outras pessoas e no reconhecimento recíproco. A partir disso, o recém-nascido é identificado como pessoa de relação e sentido, ou seja, ele tem a garantia de ser portador de direitos humanos. Segundo o filosofo alemão, "Os pais não apenas falam sobre a criança que cresce in utero, mas, de certo modo, também já se comunicam com ela". A consequência disso é que a "vida pré-pessoal" tem valor integral como um ser eticamente completo. Assim, a dignidade humana precisa ser vista no contexto da comunidade moral dos sujeitos livres e iguais de direitos humanos. ${ }^{32}$

De modo semelhante, Hannah Arendt chama atenção para a crença fundamental na santidade da vida que foi afirmada pelo cristianismo. Segundo ela, "A ênfase

\footnotetext{
27 " $[. .$.$] a right to life must be based on the capacity to want to go on living, or on the ability to see oneself$ as a continuing mental subject [...] a newborn baby cannot have a right to life." SINGER, 1999, p. 171.

28 "[...] infanticide can only be equated with abortion when those closest to the child not want it to live". SINGER, 1999, p. 173.

29 DINIZ, Debora; GUILHELM, Dirce. O que é Bioética. São Paulo: Brasiliense, 2002. p. 54-56.

${ }^{30}$ Cf. SINGER, 1999, p. 11.

${ }^{31}$ HABERMAS, Jürgen. O Futuro Da Natureza Humana: A Caminho De Uma Eugenia Liberal? São Paulo: Martins Fontes, 2004.

32 HABERMAS, 2004, p. 53.
} 
colocada pelo cristianismo na inviolabilidade da vida tendia a nivelar, anulando-as, as antigas distinções e expressões da vita activa; tendia a ver o labor, o trabalho, e a ação como igualmente sujeitos às vicissitudes da vida na terra" ${ }^{33}$. De acordo com Habermas, Arendt abordou o conceito de natalidade enquanto aspecto fundamental da dignidade humana: "Para ela, a profecia bíblica 'Um menino nos nasceu' reflete um sentido escatológico em todo nascimento, com o qual se une a esperança de que um totalmente outro quebre a corrente do eterno retorno" 34 . A partir dessa perspectiva escatológica, o cristianismo concebe o valor de cada ser humano como um elemento inalienável.

O critério utilitarista, por outro lado, entende que uma ação correta é aquela que traz benefício e felicidade igual, ou maior, para todos os atingidos pela decisão. A mentira, por exemplo, não é um mal em si mesma, uma vez que são suas consequências para o bem geral que devem ser analisadas. $\mathrm{O}$ critério moral, ao se optar ou não pela mentira, é, neste caso, a maximização da felicidade e do prazer $^{35}$ das pessoas que são afetadas por ela. ${ }^{36}$ A partir disso, para o autor australiano, o utilitarismo é uma ética de interesses das pessoas conscientes de seu passado e futuro, sem considerar a felicidade daqueles que não são conscientes - e que, portanto, não são pessoas -, como os fetos e recém-nascidos. $\mathrm{O}$ aborto legal deveria ter como critério ético a felicidade da maioria das pessoas, mesmo que trouxesse a eliminação de uma vida que ainda não estivesse consciente de si mesma.

A diferença do status moral de um feto com síndrome de Down, e de uma criança nas mesmas condições, não pode ser erigida quando o parâmetro utilizado é balizado pela compreensão utilitarista da ética. Uma vez que o interesse último dos pais deve ser respeitado, pois esses estão buscando uma vida mais feliz e sem distúrbios de consciência, não parece ser possível sustentar uma argumentação que possibilite a eliminação do feto ao mesmo tempo em que se rejeita a eliminação da criança fora do útero. Como afirma Henrik Friberg-Fernros, "Se o objetivo é evitar se tornar pais de uma criança com síndrome de Down extinguindo-a, o infanticídio é mais seguro que o aborto"37.

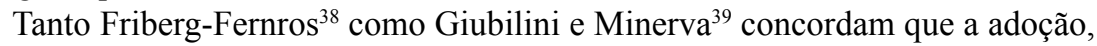
embora se apresente como alternativa aparentemente viável para o infanticídio, não é solução definitiva, tendo em vista o fato de que, se o aborto objetiva fornecer escape

${ }^{33}$ ARENDT, Hannah. Condição humana. Trad. Roberto Raposo. 10. ed. Rio de Janeiro: Forense Universitária, 2008. p. 329.

${ }^{34}$ HABERMAS, 2004, p. 81.

${ }^{35}$ O utilitarismo tem sua origem sistemática em Jeremy Bentham (1748-1832). Na visão deste filósofo inglês, os humanos são guiados pelo binômio prazer-dor. A felicidade emergiria quando o prazer se sobrepusesse hegemonicamente. SANDEL, M. J. Justice: what's the right thing to do? New York: Farrar, Straus and Giroux, 2009.

${ }^{36}$ Cf. SINGER, 1999, p. 30.

37 " [...] if the aim is to avoid becoming a parent of a child with Down syndrome by extinguishing it, infanticide is safer than abortion." FRIBERG-FERNROS, 2017, p. 15.

${ }^{38}$ FRIBERG-FERNROS, 2017. É importante notar que Friberg-Fernros não está aderindo à ética utilitarista. Sua afirmação sobre a inviabilidade da adoção como solução para esses casos se insere na crítica que faz aos que defendem o aborto de maneira generalizada, mas opõem-se ao infanticídio.

39 GIUBILINI; MINERVA, 2012, p. 3. 
para o sofrimento dos pais, as consequências psicológicas de se colocar um filho em adoção podem ser também negativas. Assim, a fim de evitar problemas para a plenitude da vida familiar, justificar-se ia o uso do infanticídio. Giubilini e Minerva, alunos do filósofo australiano Peter Singer, sintetizam esse argumento da seguinte forma: “[...] afirmamos que matar um recém-nascido pode ser eticamente permissível em todas as circunstâncias em que o aborto seria. Tais circunstâncias incluem casos em que o recém-nascido tem o potencial de ter uma vida (pelo menos) aceitável, mas o bem-estar da família está em risco" ${ }^{\$ 4}$. Embora os autores não limitem a possibilidade para casos de mutações genéticas, parece evidente que, em casos como o de síndrome de Down, a argumentação, sob essa ótica, ganharia mais força.

Segundo Peter Singer, o "assassinato de um recém-nascido" é qualitativamente diferente da execução de pessoas conscientes, como crianças e adultos, porque um bebê não tem compreensão de si no mundo. Chama atenção que Singer utiliza palavras que expressam extermínio de pessoas, como "matar" e "assassinar", quando fala sobre o aborto e o infanticídio. ${ }^{41}$ Esse vocabulário gera desconforto e críticas. A percepção das pessoas de que a proposta de Singer é escandalosa deve-se à tradição cristã, pois, para ele, como já apontado, “[...] a proteção absoluta que damos às vidas dos bebês é uma atitude especificamente cristã e não um valor ético universal"42.

Há concordância entre Arendt e as afirmações de Singer de que a vida tem dignidade e é sacrossanta em virtude da fé cristã. Para ela, "[...] o que importa hoje não é a imortalidade da vida, mas o fato de que a vida é o bem supremo. E, embora esse pressuposto seja certamente de origem cristã, não passa de circunstância importante presente à fé cristã' ${ }^{\prime 3}$. Assumir a inviolabilidade da dignidade humana, como faz o cristianismo, faz com que o ser humano seja visto como cocriador com Deus no processo de propagação da espécie. O cristianismo, desde os seus inícios, rompeu com as práticas de aborto, bem como com o infanticídio, comuns e recomendadas na antiguidade grega e romana. Assim, em virtude do conceito de santidade da vida, o fragilizado, o vulnerável, como os escravos, as mulheres e crianças, passaram a ser vistos com dignidade. ${ }^{44}$

\section{Da vida nas ruínas do cristianismo}

Apontando para o supracitado estranhamento gerado por suas propostas, Singer afirma que "a mudança das atitudes ocidentais diante do infanticídio desde a época

40 " $[\ldots]$ we claim that killing a newborn could be ethically permissible in all the circumstances where abortion would be. Such circumstances include cases where the newborn has the potential to have an (at least) acceptable life, but the well-being of the family is at risk." GIUBILINI; MINERVA, 2012, p. 2.

${ }^{41}$ SINGER, 1999.

42 "[...] our present absolute protection of the lives of infants is a distinctively Christian attitude rather than a universal ethical value." SINGER, 1999, p. 172.

${ }^{43}$ ARENDT, 2008, p. 332.

${ }^{44}$ ARENDT, 2008, p. 329; ENGELHARDT JUNIOR, H. Tristram. Fundamentos da Bioética. Trad. José A. Ceschin. 2. ed. São Paulo: Loyola, 2004. p. 33; JONAS, Hans. Das Prinzip Hoffnung: Versuch einer Ethik für die technologische Zivilisation. 17. ed. Frankfurt: Suhrkamp, 2000. p. 392-393 
romana é um produto da cristandade - assim como a doutrina do caráter sagrado da vida humana, da qual faz parte" ${ }^{45}$. A tradição cristã é latente em nossa sociedade, bem como no direito moderno. Singer faz notar as raízes cristãs de Immanuel Kant e Habermas. É necessário lembrar que, de fato, a linhagem humanista, considerada judaico-cristã, está representada por seu principal intérprete, Kant. Segundo Singer, Kant, assim como Habermas, era um filósofo religioso. Ele é "um cristão dos mais devotos" ${ }^{\prime 46}$, afirma.

O filósofo Sérgio Paulo Rouanet, membro da Academia Brasileira de Letras, em seu prefácio à obra da antropóloga Débora Diniz, proeminente defensora, no Brasil, da descriminalização do aborto, indica que duas linhagens éticas competem na contemporaneidade. A primeira se enraíza em Kant e no iluminismo, a segunda em Friedrich Nietzsche. Diniz, a quem o autor faz referência, localiza-se na segunda tradição. Para ela, assim como para Singer, não há imoralidade na eliminação de um feto. Para o filósofo australiano, "Talvez hoje seria possível examinar essas questões sem adotar a estrutura moral cristã que, por tanto tempo, impediu toda e qualquer reavaliação essencial" ${ }^{37}$. Diniz parece concordar com o autor, ao enfatizar que "[...] a religião deve ser matéria de ética privada, e políticas publicas da saúde não devem ser fundamentadas em místicas religiosas sobre o bem-viver"48.

Habermas, ao contrário de Singer e de Diniz, afirma a dignidade do ser humano a partir da concepção bíblica de que ele é imago Dei (Gn 1.27), "Deus criou o homem à sua imagem, à imagem de Deus o criou". Para ele, mesmo o ser humano secularizado concorda com a dignidade do indivíduo como um bem universal. ${ }^{49} \mathrm{De}$ fato, tal percepção pode ser notada pela legitimidade da qual a Declaração Universal dos Direitos Humanos goza diante da comunidade internacional. "Ninguém duvida do valor intrínseco da vida humana antes do nascimento [...]”, afirma Habermas, “[...] quer chamamos simplesmente de 'sagrada', quer recusemos tal 'sacralização' daquilo que constituiu um fim em si mesmo." ${ }^{50}$ Da perspectiva kantiana, os direitos humanos, baseados na razão, são indisponíveis. A dignidade humana é inegociável. ${ }^{51}$

De acordo com o filósofo H. Tristram Engelhardt, a secularização proporcionou a superação das estruturas cristãs da sociedade..$^{52}$ Nietzsche, sujeito e agente do

45 "The change in Western attitudes to infanticide since Roman times is, like the doctrine of the sanctity of human life of which it is a part, a product of Christianity." SINGER, 1999, p. 171.

46 "[...] a most pious Christian." SINGER, 1999, p. 4.

47 "Perhaps it is now possible to think about these issues without assuming the Christian moral framework that has, for so long, prevented any fundamental reassessment." SINGER, 1999, p. 173.

${ }^{48}$ DINIZ, Débora. Estado laico, objeção de consciência e políticas de saúde. Cadernos de Saúde Pública, v. 29 , n. 9 , p. $1.704-1.706,2013$. p. 1.704 .

${ }^{49}$ HABERMAS, Jürgen. Fé e Saber. In: HABERMAS, Jürgen. O futuro da Natureza Humana: A Caminho de uma Eugenia Liberal? São Paulo: Martins Fontes, 2004. p. 152-154.

${ }^{50}$ HABERMAS, 2004. p. 46.

${ }^{51}$ SANDEL, 2009.

52 ENGELHARDT JUNIOR, H. Tristram. The demoralization and deflation of Morality and Bioethics. Revista Bioethikos, v. 8, n. 3, p. 297-329, 2014. 
contexto da "morte de Deus", deixa evidente a moralidade que subsidia a formatação ética de seus intérpretes:

Moral para médicos - O doente é um parasita da sociedade. Quando se chega a certo estado, não é conveniente viver mais tempo. A obstinação em vegetar covardemente escravo de médicos e práticas médicas quando já se perdeu o sentido da vida e o direito da vida deveria inspirar à sociedade um desprezo profundo. Os médicos poderiam ser intermediários desse desgosto: nada de receitas, que com cada novo dia caia sobre os enfermos uma nova dose de tédio ${ }^{53}$.

Segundo o filósofo alemão, a sociedade deveria desprezar o doente, e os médicos deveriam ser os mediadores e agentes do desprezo aos enfermos e fracos. Ao contrário de sua posição, no entanto, os médicos continuam cuidando daqueles que merecem o desprezo da sociedade. De acordo com Nietzsche, foi Jesus que introduziu a ideia de que o doente e o fraco têm dignidade e que suas vidas têm valor. ${ }^{54}$ Assim, tanto os médicos como a população em geral, ainda que secularizados, continuam cristãos na medida em que eles cuidam dos "parasitas da sociedade". Rejeitar o cuidado a esses parasitas deveria ser a "moral dos médicos", segundo título da passagem acima.

Nesse cenário, que Engelhardt chama de "ruínas do cristianismo", a modernidade "tem tentado preservar a moralidade cristã sem a cristandade e sem Cristo [...]" ${ }^{\prime 55}$, e os indivíduos " [...] agem de acordo com o postulado de que Deus não existe" ${ }^{\text {" }}$. Nesse sentido, a negativa da transcendentalidade dos autores supracitados reverte-se em um relativismo ético que desqualifica a dignidade humana, configurando-se como busca da

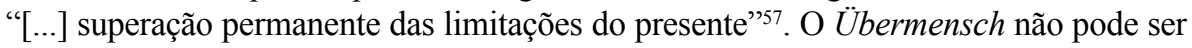
limitado pelos cuidados requeridos por uma criança considerada "normal". Que teria ele, então, a ver com alguma que fosse afetada por uma anomalia genética?

Podemos retomar a questão da imago Dei como sendo aspecto fundamental na discussão sobre a dignidade humana, numa contraposição à postura utilitarista. A partir da teologia, a questão do ser humano como imagem e semelhança de Deus é condição para falar da dignidade humana. Desse modo, também a vida humana intrauterina tem dignidade, pois ela é vista na perspectiva de Gênesis 1.27. Essa dignidade é conferida por Deus e não é atributo e qualidade intrínsecos dos seres humanos. Segundo Brakemeier, "Também a pessoa pecadora continua sendo sagrada, propriedade

${ }^{53}$ NIETZSCHE, Friedrich. Crepúsculo dos Ídolos ou A Filosofia a Golpes de Martelo. Trad. Edson Bino e Márcio Pugliesi. Curitiba: Hemus, 2001. p. 76-77.

${ }^{54}$ Cf. NIETZSCHE, 2001.

55 "Modernity has attempted to preserve Christian morality without Christianity and without Christ [...]". ENGELHARDT JUNIOR, 2014, p. 300-301.

${ }^{56}$ ENGELHARDT JUNIOR, 2014, p. 199.

57 ROUANET, Sérgio Paulo. Prefácio. In: DINIZ, Debora. Conflitos morais e bioética. Brasília: Letras Livres, 2001. p. 17. 
de Deus e pessoa amada - assim como o assassino Caim recebeu de Deus uma marca para protegê-lo da vingança na sociedade (Gn 4.15)"'58.

É na medida em que se realiza o afastamento da tradição cristã que o infanticídio tem espaço para se colocar como alternativa contra a infelicidade do coletivo. Assim como a prática do aborto se justificaria na ausência de consciência do feto, também o recém-nascido poderia ser eliminado por uma decisão dos seus progenitores. ${ }^{59}$ A esse respeito é desnecessário afirmar que Singer e também Diniz propõem uma descristianização generalizada, necessária para que as condições culturais e morais sejam apropriadas, e o infanticídio seja aceito como eticamente sustentável. Engelhardt, ao referir-se a esse assunto, aponta para muitos cidadãos que, embora secularizados, "sentem uma justificada inquietação ao ver sua sociedade voltar às práticas de um passado pluralista pagão"60.

Nesse sentido, retoma-se Arendt para argumentar que o mal-estar, mencionado por Engelhardt, está relacionado também com o gradual abandono da ideia de que a procriação como perspectiva de esperança de futuro está fundamentada nos relatos da criação (Gn 1.27), bem como na encarnação de Deus em Jesus Cristo, ou seja, na cristologia. ${ }^{61}$ Segundo ela, a procriação é "o milagre" que garante a salvação do mundo, pois no nascimento acontece um novo começo que se estende para o futuro. Enquanto houver procriação, haverá fé e esperança como elementos fundamentais da existência humana. Essa perspectiva escatológica da vida humana foi resumida "nas breves palavras com as quais os Evangelhos anunciaram a 'boa nova': 'nasceu uma criança entre nós" "'62.

A linguagem decorrente do pensamento de Nietzsche, bem como a bioética relativista de Peter Singer, Francesca Minerva, Alberto Giubilini e Débora Diniz, deveria ser transformada em projetos de políticas públicas. A partir desses teóricos, é possível depreender que a cultura ocidental precisa ser devidamente modificada, para fazer com que os fetos ou crianças, considerados ora "vidas inúteis", ora "fardos", mas sempre indesejados, sejam eliminados. Esse é o núcleo do pensamento de Singer, que sugere a superação da ideia cristã de um estado liberal democrático, que tem a função e o propósito de cuidar de pessoas fragilizadas. ${ }^{63}$

${ }^{58}$ BRAKEMEIER, Gottfried. O ser humano em busca de identidade: contribuições para uma antropologia teológica. São Leopoldo: Sinodal; São Paulo: Paulus, 2002. p. 25.

59 Cabe observar que tal cenário levanta uma problemática extra, uma vez que a decisão dos pais em, por exemplo, manter a gravidez no caso de alguma anomalia fetal ser detectada, pode gerar insatisfação e infelicidade para o restante da sociedade, prejudicando o máximo prazer buscado pelos utilitaristas.

${ }^{60}$ ENGELHARDT JUNIOR, 2004, p. 333.

${ }^{61}$ ARENDT, 2008, p. 15-19.

62 ARENDT, 2008, p. 259.

${ }^{63}$ Cf. SINGER, 1999. 


\section{Considerações finais}

Tendo em vista o cenário exposto acima, propomos que se reconheça a consequência lógica de uma postura que zela pela garantia da felicidade e do bem-estar, não só da família das mulheres que tiveram um diagnóstico preciso e interromperam sua gravidez, mas também das mulheres que, por qualquer motivo, acabaram dando à luz uma criança com o código genético alterado pela trissomia 21, ou qualquer outra condição genética. Embora o utilitarismo fundamente a interrupção da gravidez, independentemente da condição de saúde do feto, parece particularmente claro que a maximização da felicidade dos envolvidos, como os exemplos citados no início do texto demonstram, é uma justificativa comumente utilizada nos casos de diagnóstico de anomalias genéticas.

Ainda que se possa questionar a validade das argumentações de fundo religioso, como faz equivocadamente Diniz ${ }^{64}$ - ao reduzir os críticos de sua postura à fé que esses professam -, não parece ser possível fugir da consequência da adoção do critério da felicidade como motivador para a eliminação do feto. O infanticídio se mostra como um procedimento mais seguro, e que faz justiça, nos parâmetros éticos elencados, à felicidade da mulher, que não deveria ser afetada por incômodos decorrentes de complicações na formação do embrião.

A ausência de universais éticos, como aqueles oferecidos pela tradição cristã, possibilita a viabilidade de aceitação moral do infanticídio. Como se procurou demonstrar pela convergência entre a concepção humanista da dignidade da vida em Habermas e Arendt, bem como pela confissão da santidade da vida na tradição cristã, a dignidade humana, conferida por Deus, escapa ao relativismo, e postula sua inviolabilidade. Mesmo o ser humano caído na realidade do pecado e da morte não deixa de ser imagem de Deus.

Sugerimos, a partir do que foi apresentado, que qualquer oposição ao infanticídio de crianças com síndrome de Down deve também, para ser coerente com seus critérios, rejeitar o abortamento seletivo de fetos por motivos quaisquer, sejam eles sexuais ou por anomalias genéticas. Nesse sentido, retomamos a leitura ética dos autores citados, reafirmando que a conclusão de uma postura moralmente relativista da vida humana, e a consequência geral da adoção de uma política de aborto seletivo em nome da qualidade de vida, é a abertura do caminho que leva ao after-birth abortion, o infanticídio.

\section{Referências}

ARENDT, Hannah. Condição humana. 10. ed. Trad. Roberto Raposo. Rio de Janeiro: Forense Universitária, 2008.

BINGHAM, John. Richard Dawkins: 'immoral' to allow Down's syndrome babies to be born. The Telegraph, 2014. Disponível em: <https://www.telegraph.co.uk/news/health/news/11047072/

${ }^{64}$ DINIZ, 2013. 
Richard-Dawkins-immoral-to-allow-Downs-syndrome-babies-to-be-born.html>. Acesso em: 29 out. 2018.

BOYD, P. A. et al. Survey of prenatal screening policies in Europe for structural malformations and chromosome anomalies, and their impact on detection and termination rates for neural tube defects and Down's syndrome. Bjog, v. 115, n. 6, p. 689, 2008.

BRAKEMEIER, Gottfried. O ser humano em busca de identidade: contribuições para uma antropologia teológica. São Leopoldo: Sinodal; São Paulo: Paulus, 2002.

BURKE, Dave. Outcry after French court rules that pro-life commercial showing happy children with Down syndrome was 'inappropriate' and 'likely to disturb women' who had abortions. Dailymail, 2016. Disponível em: <https://www.dailymail.co.uk/news/article-3970656/Outcry-French-court-rules-pro-life-commercial-showing-happy-children-syndrome-inappropriate-likely-disturb-women-abortions.html>. Acesso em: 29 out. 2018.

COLE, Robert; JONES, David. Testing times: do new prenatal tests signal the end of Down syndrome? The New Zealand medical journal, v. 126, p. 96-102, 2013.

CREMESP - CENTRO DE BIOÉTICA. STF promove audiência pública sobre o Início da Vida. CREMESP - Centro de Bioética, 2018. Disponível em: <http://www.bioetica.org. br/?siteAcao=Destaques\&id=91>. Acesso em: 29 out. 2018.

DAWKINS, Richard. Abortion \& Down Syndrome: An Apology for Letting Slip the Dogs of Twitterwar. Richard Dawkins, 2014. Disponível em: <https://www.richarddawkins.net/2014/08/ abortion-down-syndrome-an-apology-for-letting-slip-the-dogs-of-twitterwar/>. Acesso em: 29 out. 2018.

DINIZ, Débora. Estado laico, objeção de consciência e políticas de saúde. Cadernos de Saúde Pública, v. 29, n. 9, p. 1.704-1.706, 2013.

DINIZ, Debora; GUILHELM, Dirce. O que é Bioética. São Paulo: Brasiliense, 2002.

ENGELHARDT JUNIOR, H. Tristram. Fundamentos da Bioética. Trad. José A. Ceschin. 2. ed. São Paulo: Loyola, 2004.

ENGELHARDT JUNIOR, H. Tristram. The demoralization and deflation of Morality and Bioethics. Revista Bioethikos, v. 8, n. 3, p. 297-329, 2014.

FRIBERG-FERNROS, Henrik. Clashes of consensus: on the problem of both justifying abortion of fetuses with Down syndrome and rejecting infanticide. Theoretical Medicine and Bioethics, v. 38, n. 3, p. 195-212, 2017.

GIUBILINI, Alberto; MINERVA, Francesca. After-birth abortion: why should the baby live? Journal of Medical Ethics, p. medethics-2011-100411, 2012.

GOLLOP, Thomaz Rafael. Aborto por Anomalia Fetal. Revista Bioética, v. 2, n. 1, 2009.

HABERMAS, Jürgen. Fé e Saber. In: HABERMAS, Jürgen. O futuro da Natureza Humana: A Caminho de uma Eugenia Liberal? São Paulo: Martins Fontes, 2004.

HABERMAS, Jürgen. O Futuro Da Natureza Humana: A Caminho De Uma Eugenia Liberal? São Paulo: Martins Fontes, 2004.

JONAS, Hans. Das Prinzip Hoffnung: Versuch einer Ethik für die technologische Zivilisation. 17. ed. Frankfurt: Suhrkamp, 2000.

MARCUS, Ruth. I would've aborted a fetus with Down syndrome. Women need that right. Washington Post, 2018. Disponível em: $<$ https://www.washingtonpost.com/opinions/i-wouldve-aborted-a-fetus-with-down-syndrome-women-need-that-right/2018/03/09/3aaac364-23d6-1 1e8-94da-ebf9d112159c_story.html?utm_term=.83dc1a90867b>. Acesso em: 29 out. 2018.

NIETZSCHE, Friedrich. Crepúsculo dos İ́dolos ou A Filosofia a Golpes de Martelo. Trad. Edson Bino e Márcio Pugliesi. Curitiba: Hemus, 2001.

NORWITZ, Errol R.; LEVY, Brynn. Noninvasive Prenatal Testing: The Future Is Now. Reviews in Obstetrics and Gynecology, v. 6, n. 2, p. 48-62, 2013. 
REILLY, Gavan. Vitória pró-aborto na Irlanda surpreende até mesmo ativistas. Deutsche Welle, 2018. Disponível em: <https://www.dw.com/pt-br/vit\%C3\%B3ria-pr\%C3\%B3-aborto-na-irlanda-surpreende-at\%C3\%A9-mesmo-ativistas/a-43951449>. Acesso em: 29 out. 2018.

ROUANET, Sérgio Paulo. Prefácio. In: DINIZ, Debora. Conflitos morais e bioética. Brasília: Letras Livres, 2001.

SANDEL, M. J. Justice: what's the right thing to do? New York: Farrar, Straus and Giroux, 2009. SINGER, Peter. Practical Ethics: Second Edition. New York: Cambridge University Press, 1999. SCHREIBER, Mariana. Senado argentino barra legalização do aborto; países latino-americanos são os que mais restringem a prática no mundo. BBC Brasil, 2018. Disponível em: $<$ https://www. bbc.com/portuguese/geral-45126092>. Acesso em: 29 out. 2018.

SKOTKO, Brian G.; LEVINE, Susan P.; GOLDSTEIN, Richard. Self-perceptions from People with Down Syndrome. American journal of medical genetics, Part A, v. 0, n. 10, p. 2.360-2.369, 2011. 